\title{
Bacillus subtilis as a bioindicator for estimating pentachlorophenol toxicity and concentration
}

\author{
M. A. Ayude $\cdot$ E. Okada $\cdot$ J. F. González $\cdot$ \\ P. M. Haure $\cdot$ S. E. Murialdo
}

Received: 30 December 2008/Accepted: 12 February 2009/Published online: 10 March 2009

(C) Society for Industrial Microbiology 2009

\begin{abstract}
Pentachlorophenol (PCP) and its sodium salt (Na-PCP) are extremely toxic chemicals responsible for important soil and groundwater pollution, mainly caused by wastes from wood-treatment plants, because chlorinated phenols are widely used as wood preservatives. The methods most commonly used for routine analysis of pesticides such as PCP and Na-PCP are high-performance liquid chromatography (HPLC) and gas chromatographymass spectroscopy (GC-MS). A variety of rapid biological screening tests using marine organisms, bioluminescent bacteria, and enzymes have also been reported. In this study, rapid biological screening analysis using Bacillus subtilis was developed, to assess the biodegradation of PCP and its by-products in liquid samples. An empirical model is proposed for spectrophotometric analysis of Na-PCP concentration after growth of Bacillus subtilis.
\end{abstract}

Keywords Pentachlorophenol - Bacillus subtilis .

Bioindicators · Toxicity assessment

\section{Introduction}

Substantial amounts of chlorinated aromatic compounds, including chlorophenols, have been discharged into the

\footnotetext{
M. A. Ayude $(\bowtie) \cdot$ P. M. Haure

Div. Catálisis, INTEMA, Facultad de Ingeniería,

Universidad Nacional de Mar del Plata (UNMdP),

Mar del Plata, Argentina

e-mail: mayude@fi.mdp.edu.ar

E. Okada · J. F. González · S. E. Murialdo $(\bowtie)$

Grupo de Ingeniería Bioquímica (GIB),

Departamento de Ingeniería Qca, Facultad de Ingeniería,

UNMdP, Mar del Plata, Argentina

e-mail: silviem@fi.mdp.edu.ar
}

environment [1]. Chlorination of phenol greatly increases the toxicity of the resulting molecules relative to phenol, consequently pentachlorophenol (PCP and Na-PCP) is by far the most studied because of its high toxicity. PCP and Na-PCP are extremely toxic chemicals responsible for important soil and groundwater pollution, principally from wood-treatment plants, because chlorinated phenols are widely used as wood preservatives. At least, 32 photolytic or biodegradation products of PCP and Na-PCP have been identified, including: octachlorodibenzo- $p$ dioxin, tetrachlororesorcinol, tetrachloro, trichloro, and dichlorophenols, pentachloro, tetrachloro, trichloro, and dichloroanisoles, and tetrachlorohydroquinone [2]. Many of these constituents are potentially toxic, mutagenic, or teratogenic [3].

The most commonly employed methods for routine analysis of pesticides such as PCP and Na-PCP are high-performance liquid chromatography (HPLC) and gas chromatography-mass spectroscopy (GC-MS). These methods enable reliable analysis of compounds at the trace level but require sophisticated and expensive equipment. The most promising alternatives in environmental toxicology include the use of biomolecules and organisms with limited sensitivity, for example enzymes, bacteria, fungi, and algae [4]. For example, in toxicity assays (Microtox (Azure, Bucks, UK) or ToxAlert (Merck, Darmstadt, Germany)), whole organisms are used to measure the toxicity of water and soil samples. These systems are based on use of the luminescent bacteria Vibrio fischeri to measure the toxicity of environmental samples. Furthermore, Escherichia coli has been genetically modified with lightproducing genes and, under normal conditions, give out visible light (bioluminescence) [5, 6]. Young et al. [4] investigated the effect of PCP on two isozymes of lactate dehydrogenase (LDH) and found that detection limits can 
be significantly reduced by modification of enzyme inhibition assays with a non-optimum cofactor.

Repetto et al. [7] studied the specific effect of PCP using different ecotoxicological model systems, including immobilization of Daphnia magna, bioluminiscence inhibition in the bacterium Vibrio fischeri, growth inhibition of the alga Chlorella vulgaris, and micronuclei induction in the plant Allium cepa. PCP was very toxic to all biota and cells; micronuclei induction in Allium cepa was the most sensitive.

The evolution of toxicity and biodegradability of liquid streams from oxidation treatments should be evaluated, in order to effectively assess the impact of discharge of xenobiotics on the biota of the receiving water bodies. In this sense, bioassays provide an alternative because they constitute a measurement of environmentally relevant toxicity. In this study, a method for rapid biological screening analysis was developed to assess the biodegradation of Na-PCP, and the presence of toxic by-products in liquid samples. An empirical model is proposed for simple spectrophotometric $\left(A_{600}\right)$ estimation of Na-PCP concentration after growth of Bacillus subtilis.

\section{Materials and methods}

\section{Chemicals and reagents}

Pentachlorophenol (99\% pure) was obtained from Sigma Chemical (St Louis, MO, USA). The salt sodium pentachlorophenate (Na-PCP) was used in all assays. All chemicals used were of the highest purity available commercially.

\section{PCP mineralization}

Mixed culture [8] able to degrade Na-PCP, was inoculated in mineral salts (MS) solution (in grams per litre: $\mathrm{NaNO}_{3} 2.25, \mathrm{~K}_{2} \mathrm{HPO}_{4} 2.83, \mathrm{KH}_{2} \mathrm{PO}_{4} 0.507, \mathrm{MgSO}_{4} .7$ $\mathrm{H}_{2} \mathrm{O} 0.45, \mathrm{FeSO}_{4}$ 0.135, and $\mathrm{CaCl}_{2}$ 0.45) plus Na-PCP as the only source of carbon and energy (NaPCP-MS medium). Details on culture conditions and media are given in Murialdo et al. [8]. Acclimated cells in NaPCPMS liquid medium containing $25-500 \mathrm{mg} / \mathrm{l} \mathrm{Na-PCP}$ were used as the inoculum for all Na-PCP degradation and toxicity experiments. Batch culture experiments were carried out in $250 \mathrm{ml}$ Erlenmeyer flasks filled with $50 \mathrm{ml}$ NaPCP-MS medium, and attached to a shaker (120 rpm) at $25^{\circ} \mathrm{C}$.

Liquid samples were periodically withdrawn and filtersterilized (pore size $0.22 \mu \mathrm{m}$ ) for further analysis. Na-PCP content was determined with a Shimadzu UV-visible spectrophotometer by comparison with a standard curve
$($ Na-PCPAbs $320=1$ corresponds to $50 \mathrm{mg} / \mathrm{l})$. The flasks were kept at $25^{\circ} \mathrm{C}$ in the dark to avoid photo-decomposition of Na-PCP. In each experiment a flask with no inoculum was run as control for Na-PCP volatilisation [9].

\section{Toxicity bioassays}

A suspension of the bacterium Bacillus subtilis ATCC 6051 sensitive to the bactericidal action of PCP and many of its metabolites [10] was used. Samples taken periodically from batch Na-PCP-biodegradation experiments were filter-sterilized (pore size $0.22 \mu \mathrm{m}$ ). Different dilutions, in the range $1 / 2$ to $1 / 128$, were made in tryptone broth (TB), and these were then inoculated with B. subtilis $(10 \% v / v)$ previously grown in TB overnight. After incubation times of $48 \mathrm{~h}$ at $120 \mathrm{rpm}$ and $25^{\circ} \mathrm{C}$, the growth of B. subtilis was assessed by $A_{600}$. The results were compared with the output of B. subtilis ATCC 6051 exposed to different dilutions of Na-PCP in TB. The concentrations of Na-PCP were determined by HPLC (Shimadzu LC-10AD). Parallel to this assay, the last sample depleted of Na-PCP was also analyzed by HPLC in order to confirm the disappearance of Na-PCP and its by-products.

Additional experiments were performed to quantify and correlate the bacterial growth with $A_{600}$. Bacteria were grown in an Erlenmeyer flask with $0.5 \mathrm{mg}$ dehydrated LB medium powder per millilitre at $25^{\circ} \mathrm{C}$. After $24 \mathrm{~h}$ of incubation the cells were collected at $14,000 \mathrm{rpm}$. The cells were re-suspended in $2 \mathrm{ml}$ phosphate buffer. Serial dilutions were made and $A_{600}$ was determined using a Shimadzu UV-visible spectrophotometer. Each dilution was surface plated on $0.5 \mathrm{~g}$ dehydrated LB medium, and $1.5 \mathrm{~g}$ of agar per $100 \mathrm{ml}$. The plates were incubated at $25^{\circ} \mathrm{C}$, and the colonies were counted after $48 \mathrm{~h}$ and expressed as colony-forming units per milliliter ( $\mathrm{CFU} / \mathrm{ml})$. Dry weight was determined by weighing the cells after drying in an oven at $105^{\circ} \mathrm{C}$ for $24 \mathrm{~h}$. Figure 1 shows the correlation of $\mathrm{CFU} / \mathrm{ml}$ and dry weight as a function of $A_{600}$.

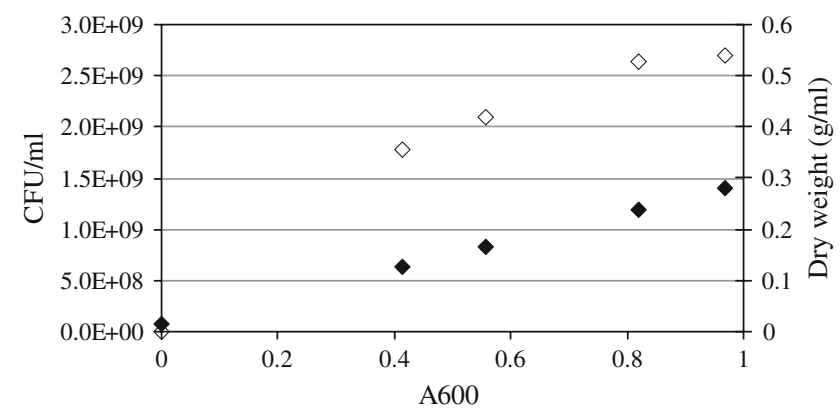

Fig. 1 Colony-forming units per millilitre (filled diamonds) and dry weight (open diamonds) as a function of $A_{600}$ for $B$. subtilis growth 
Statistical analysis

All yield measurements were performed three times in duplicate. Statistically significant differences between $A_{600}$ measurements were evaluated by use of Excel software. The significance levels are quoted at the $95 \%$ confidence level $(P \leq 0.05)$.

\section{Results and discussion}

Estimation of Na-PCP using B. subtilis as a bioindicator

\section{Control assay}

Na-PCP toxicity to Bacillus subtilis was investigated using a known concentration of Na-PCP in a control assay. Results are presented in Fig. 2. Cell growth was apparent when the absorbance at $600 \mathrm{~nm}$ was greater than 0.1 . Thus, B. subtilis was not able to grow when Na-PCP concentration was above $1.5 \mathrm{mg} / \mathrm{l}$, and maximum growth was achieved without Na-PCP.

The dependence on Na-PCP concentration of B. subtilis growth for Na-PCP concentrations below $1.5 \mathrm{mg} / \mathrm{l}$ was investigated thoroughly. Data were correlated using the nonlinear regression package MathCad (genfit function) as:

$\mathrm{PCP}(\mathrm{mg} / \mathrm{l})=\frac{0.4036}{\mathrm{~A}_{600}}-0.3321$

This method is suitable for predicting responses for $A_{600}>0.1$. The maximum growth of $B$. subtilis during $48 \mathrm{~h}$ of incubation corresponds to an absorbance $\left(A_{600}\right)$ of approximately 1 . Figure 2 shows that fitting is more accurate for $A_{600}>0.2$, which is for Na-PCP content below $1 \mathrm{mg} / \mathrm{l}$. Therefore, monitoring the growth of B. subtilis by use of $A_{600}$ enables estimation of Na-PCP concentration.

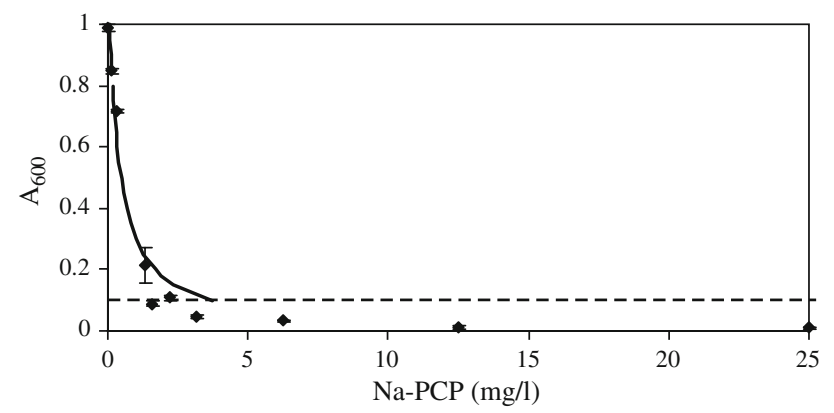

Fig. 2 Control assay: filled diamonds, experimental data; solid line, genfit fitting; dashed line, $A_{600}=0.1$ (the dashed line represents the value above which the growth of $B$. subtilis can be observed spectrophotometrically)

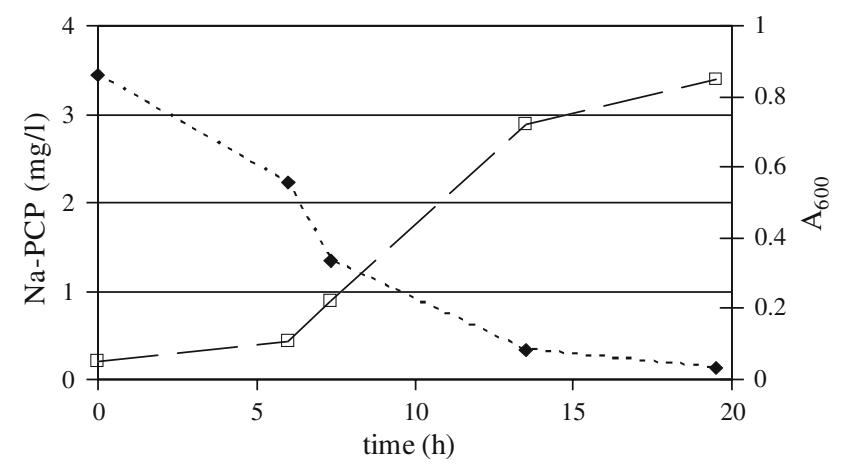

Fig. 3 Effect of residual PCP concentration on B. subtilis growth in culture media (with PCP-SM) where mixed culture has previously been grown: filled diamonds, Na-PCP (m/l); open squares, $A_{600}$

Na-PCP mineralisation: toxicity screening

Na-PCP mineralisation experiments, using mixed culture [8], were performed in a batch reactor. Samples were periodically withdrawn and centrifuged. Na-PCP concentration was determined by $A_{320}$. Then, samples were filter sterilized (pore size $0.22 \mu \mathrm{m}$ ) and diluted (1/32) in TB before inoculating $B$. Subtilis in order to analyze the dependence of the growth of $B$. subtilis in media previously treated with mixed culture. Results are presented in Fig. 3. These outcomes effectively demonstrate that the media, after being treated with mixed culture, does not contain intermediate products toxic to $B$. subtilis. This was also confirmed by parallel HPLC assays (data not shown).

For the first samples taken from the batch reactor ( 0 and $6.33 \mathrm{~h}$ ), $1 / 32$ dilution is not enough to allow $B$. subtilis growth (Fig. 3), because Na-PCP concentration is greater than $1.5 \mathrm{mg} / \mathrm{l}$. Consequently, in the whole set of samples, different dilutions in TB from 1/2 to 1/128 were made for all the samples taken in biodegradation experiments. Each dilution was then inoculated with a $B$. subtilis suspension of known concentration. This procedure is useful to determine in which range the dilution should be made to enable $B$. subtilis growth. Na-PCP concentration was determined by $A_{320}$. Results for a typical experiment are shown in Table 1 . When $A_{600} \gg 0.1$ after $48 \mathrm{~h}$ of incubation at $25^{\circ} \mathrm{C}, \mathrm{Na}-\mathrm{PCP}$ concentration was estimated using Eq. (1). Thus, the estimated Na-PCP concentration in the original sample was obtained. For the whole testing dataset, the mean relative error was $17.3 \%$.

\section{Conclusions}

The toxicity of chlorophenols varies between different congeners and bacteria. In our results we found that the minimum concentration of Na-PCP, which completely inhibited growth of B. subtilis ATCC 6051, was above 
Table 1 Results for a typical PCP biodegradation experiment

\begin{tabular}{|c|c|c|c|c|c|c|}
\hline Time (h) & $\begin{array}{l}\text { PCP in original } \\
\text { sample }(\mathrm{mg} / \mathrm{l})^{\mathrm{a}}\end{array}$ & $\begin{array}{l}\text { Sample } \\
\text { dilution }\end{array}$ & $\begin{array}{l}\text { PCP in diluted } \\
\text { sample }(\mathrm{mg} / \mathrm{l})^{\mathrm{a}}\end{array}$ & 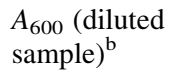 & $\begin{array}{l}\text { Estimated PCP in diluted } \\
\text { sample (Eq. 1) }(\mathrm{mg} / \mathrm{l})\end{array}$ & $\begin{array}{l}\text { Estimated PCP in } \\
\text { original sample }(\mathrm{mg} / \mathrm{l})\end{array}$ \\
\hline 0 & 110 & $1 / 128$ & 0.86 & 0.3704 & 0.76 & 96.9 \\
\hline 6 & 71 & $1 / 64$ & 1.11 & 0.3585 & 0.79 & 50.8 \\
\hline 7.3 & 43.5 & $1 / 32$ & 1.36 & 0.215 & 1.54 & 49.4 \\
\hline 13.5 & 11 & $1 / 8$ & 1.37 & 0.2095 & 1.59 & 12.7 \\
\hline
\end{tabular}

PCP estimation using B. subtilis

a Measured by $A_{320}$

b Measured after $48 \mathrm{~h}$ of incubation

$1.5 \mathrm{mg} / \mathrm{l}$. It is clear that $B$. subtilis is sensitive, specific, and useful for detecting low levels of Na-PCP concentration. The bioassay is simple, inexpensive, and fast, and does not require complex sample-preparation procedures or sophisticated analytical instrumentation. An empirical model enables estimation of Na-PCP concentration within $17.3 \%$ error. This toxicity test may therefore enable accurate assessment of the efficacy of bioremediation of contaminated soils and groundwater, especially for compounds such as Na-PCP, for which many toxic degradation by-products may exist. Several bacteria degrade PCP and $\mathrm{Na}-\mathrm{PCP}$ but there are various unknown toxic metabolic intermediates which could be detected by sensitive bacteria such as B. subtilis.

Furthermore, this work contributes an effective tool that can be used in situations in which technology presents temporary constraints. Although this research used a spectrophotometer, it avoids the use of UV light, which is necessary to detect Na-PCP. Moreover, the use of a spectrophotometer can be replaced when using the direct method of microorganism counting (CFU) or dry weight $(\mathrm{g} / \mathrm{ml})$.

Acknowledgments The authors would like to thank Dr. Claudia Studdert and Dr. Celina Martone for their support, CONICET for assisting with fellowships, SECyT for financial aid, and INTEMA, CONICET, and Universidad Nacional de Mar del Plata for facilitating the development of this research.

\section{References}

1. Steinle P, Stucki G, Stettler R, Hanselmann KW (1998) Aerobic mineralisation of 2,6-dichlorophenol by Ralstonia sp. strain RK1. Appl Environ Microbiol 64:2566-2571
2. Middaugh DP, Resnick SM, Lantz SE, Heard CS, Mueller JG (1993) Toxicological assessment of biodegraded pentachlorophenol: microtox and fish embryos. Arch Environ Contam Toxicol 24:165-172

3. Lu PRL, Metcalf E, Cole LK (1977) The environmental fate of ${ }^{14} \mathrm{C}$-pentachlorophenol in laboratory model ecosystems. In: Rao KR (ed) Pentachlorophenol: chemistry, pharmacology, and environmental toxicology. Plenum, New York, pp 53-63

4. Young J, Dowman AA, Cowell DC (1999) The detection of pentachlorophenol by its inhibitory effectiveness on lactate dehydrogenase of rabbit muscle and Bovine Heart. J Pest Biochem Physiol 64:1-8. doi:10.1006/pest.1999.2404

5. Redshaw N, Dickson SJ, Ambrose V, Horswell J (2007) A preliminary investigation into the use of biosensors to screen stomach contents for selected poisons and drugs. Forensic Sci Int 172:106-111

6. Rattray EAS, Prosser JI, Killham K, Glover LA (1990) Luminescence-based nonextractive technique for in situ detection of Escherichia coli in soil. Appl Environ Microbiol 56:3368-3374

7. Repetto G, Jos A, Hazen MJ, Molero ML, del Peso A, Salguero M, del Castillo P, Rodriguez-Vicente MC, Repetto M (2001) A test battery for the ecotoxicological evaluation of Pentachlorophenol. Toxicol In Vitro 15:503-509. doi:10.1016/S0887-2333 (01)00055-8

8. Murialdo SE, Fenoglio R, Haure PM, Gonzalez JF (2003) Degradation of phenol and chlorophenols by mixed and pure cultures. Water SA 29:457-463

9. Radehaus RM, Schmidt SK (1992) Characterization of a novel Pseudomonas sp. that mineralizes high concentrations of pentachlorophenol. Appl Environ Microbiol 58:2879-2885

10. Ruckdeschel G, Renner G, Schwarz K (1987) Effects of pentachlorophenol and some of its known and possible metabolites on different species of bacteria. Appl Environ Microbiol 53(11): 2689-2692 